\title{
Assistência Psicológica na Hemodiálise: um espaço possível para a ressignificação
}

\section{Psychological Assistance in Hemodyalysis: a possible space for ressignification}

\author{
Jéssica dos Santos Queiroz ${ }^{\dagger *}$, Juliana Fernandes de Souza Ribeiro \\ Como citar esse artigo. QUEIROZ, \\ Resumo
}

J.S.; RIBEIRO, J.F.S. Assistência

Psicológica na Hemodiálise: um espaço possível para a ressignificação. Revista Mosaico, v.12, n.1, p. 86-92, 2021

O fio condutor desse trabalho aborda o impacto da Insuficiência Renal Crônica, seu tratamento e suas implicações, o processo de hospitalização na vida desses pacientes e seu entorno e levanta reflexões acerca das restrições, perdas, mudanças, transformações decorrentes da doença. Para tanto, elucidamos a relevância do papel do psicólogo como membro do grupo de profissionais que compõe a unidade de hemodiálise e sua atuação, com o intuito de amenizar o sofrimento advindo do adoecimento e propicia uma discussão referente à possibilidade da ressignificação. Além disso, destaca-se a importância da humanização no cuidado, da identificação do indivíduo em sua totalidade, do redescobrimento do sentido da sua existência diante um cenário que propicia uma aproximação com a fragilidade e a finitude e, ainda, possibilita uma reflexão acerca da importância de ofertar uma escuta qualificada.

Nota da Editora. Os artigos publicados na Revista Mosaico são de responsabilidade de seus autores. As informações neles contidas, bem como as opiniões emitidas, não representam pontos de vista da Universidade de Vassouras ou de suas Revistas.

Palavras-chave: Psicologia; Insuficiência Renal Crônica; Ressignificação.

\begin{abstract}
The main thread of this work addresses the impact of Chronic Kidney Failure, its treatment and implications, the process of hospitalization in the lives of these patients and their surroundings and raises reflections about the restrictions, losses, changes, transformations resulting from the disease. For this purpose, we elucidate the relevance of the role of the psychologist as a member of the group of professionals that composes the hemodialysis unit and its performance, with the purpose of alleviating the suffering arising from the illness and provides a discussion regarding the possibility of resignification. In addition, the importance of humanization in care, the identification of the individual as a whole, the rediscovery of the meaning of his existence in the face of a scenario that provides an approach to fragility and finitude, and also allows a reflection on the importance of offering qualified listening.

Keywords: Psychology; Chronic Kidney Failure; Resignification.
\end{abstract}

\section{Introdução}

O presente trabalho realizado através de revisão bibliográfica, objetiva elucidar a temática sobre a prática do psicólogo junto aos pacientes renais crônicos em tratamento hemodialítico e contribuir com uma reflexão acerca da possibilidade da ressignificação através da assistência psicológica ofertada.

Buscamos compreender e dissertar sobre os comprometimentos advindos do diagnóstico de Insuficiência Renal Crônica (IRC), bem como, apresentar a crescente estatística dos indivíduos que convivem com essa patologia.

O paciente, por sua vez, passa a estar imerso ao ambiente e contexto hospitalar, com certa regularidade. Importante salientar que a Insuficiência Renal Crônica é um desafio que estabelece ao paciente algumas restrições e mudanças de hábitos, que podem ocasionar um impacto significativo no seu cotidiano, provendo, com isso, de possíveis ajustes das práticas habituais do mesmo, da família etc.

Mediante esta situação, acredita-se que é inteiramente importante ponderar a patologia, porém, não de forma exclusiva e, sim, considerar o indivíduo como um ser biopsicossocial. No artigo dispomos de aportes teóricos para compreender o processo de adoecimento e as relações entre o sofrimento físico e psíquico. Abordamos a relevância do reconhecimento da individualidade, a compreensão de possíveis fragilidades que o paciente possa estar submetido pela doença, mediante as particularidades, a habilidade de ressignificar a sua existência, entre outros aspectos que o torna único.

Afiliação dos autores:

† Pós-graduanda, curso de Psicologia Hospitalar e da Saúde, Universidade de Vassouras, Vassouras, RJ, Brasil.

* Mestre, supervisora do curso de Psicologia Hospitalar e da Saúde, Universidade de Vassouras, Vassouras, RJ, Brasil.

*Email de correspondência: jessicaq93@gmail.com 
Também faz-se necessário abordar ainda, a importância da atuação do psicólogo neste contexto com o objetivo de propiciar, através da assistência psicológica, uma possível ressignificação da existência e a promoção da qualidade de vida.

\section{Entendendo a insuficiência renal crônica, seus impactos e tratamento}

Em relação aos dados estatísticos apresentados pelo Censo da Sociedade Brasileira de Nefrologia, o quantitativo de pessoas que necessitam do processo de hemodiálise cresce de forma significativa anualmente. (SOCIEDADE BRASILEIRA DE NEFROLOGIA, 2017).

Em concordância com o Ministério da Saúde, a doença é caracterizada pela incapacidade dos rins de desenvolverem suas funções básicas. Com isso, a insuficiência renal pode apresentar-se como Insuficiência Renal Aguda (IRA), quando ocorre súbita e rápida ausência da função dos rins, ou Insuficiência Renal Crônica, quando esta perda é lenta e irreversível. Importante ressaltar, como afirma FERMI, 2003, que é de competência do nefrologista diagnosticar, visto que em sua investigação clínica, o mesmo consegue avaliar as possíveis alterações.

Os rins são responsáveis pela eliminação de toxinas através de um sistema de filtração, pela regulação da formação e da produção dos glóbulos vermelhos no sangue, pela regulação da pressão sanguínea e pelo controle químico e de líquidos do corpo (HRICIK citado por NASCIMENTO, 2013).

Importante salientar, mediante ao que REIS; GUIRARDELLO; CAMPOS (2008) dissertam que a Doença Renal Crônica (DRC) ou Insuficiência Renal Crônica (IRC), implica em um comprometimento das funções renais e afeta diretamente o indivíduo em todos os âmbitos, seja ele fisiológico, psicológico, socioeconômico, entre outros. Ao se deparar com a manifestação da enfermidade, o paciente necessita reestruturar a sua maneira de viver, adquirindo novas práticas, construindo, assim, uma nova rotina.

Conforme o Ministério da Saúde, a DRC é considerada em cinco estágios que correspondem aos níveis e às técnicas do cuidado.

Os estágios 1, 2 e 3 equivalem ao estado conservador da patologia, com o uso de remédios, recomendação de regime alimentar específico, realizações de exames, entre outras indicações que são importantes e que tem como finalidade evitar o agravamento.

O estágio 4 é denominado pré-diálise, que é efetuada a manutenção do estágio anterior e, quando os casos apresentam-se de forma grave, é iniciado o preparo para a diálise. No estágio subseqüente e último, o dialítico realiza o Tratamento Renal Substitutivo, sendo eles: a Hemodiálise, Hemodiálise Peritoneal e/ou Transplante Renal. A definição do tipo de tratamento é fundamentada na indicação médica, a partir das condições clínicas e do critério do paciente (MINISTÉRIO DA SAÚDE, 2015).

\begin{abstract}
Quando os rins já não funcionam corretamente, há a necessidade de se fazer diálise. Na maioria das vezes o tratamento deve ser feito para o resto da vida, se não houver possibilidade de ser submetido a um transplante renal. A cada ano, cerca de 21 mil brasileiros precisam iniciar tratamento por hemodiálise ou diálise peritoneal. Raros são aqueles que conseguem ter pelo menos uma parte do funcionamento dos rins recuperada o bastante para deixarem de necessitar de diálise, e poucos têm a sorte de receber um transplante renal. A cada ano somente 2.700 brasileiros são submetidos a um transplante renal. (ROMÂO citado por NASCIMENTO, 2013, p.72).
\end{abstract}

Mediante a citação acima, entende-se o transplante como uma possibilidade de tratamento para a DRC. O mesmo consiste na realização de um processo cirúrgico no qual um rim saudável de um doador (que pode ser cadáver, vivo, relacionado ou não-relacionado) é transplantado para o paciente que está sendo submetido à cirurgia, porém, o transplante é um tratamento e não a cura. BARROS citado por QUINTANA; MÜLLER (2006) nos esclarece que a compatibilidade entre o receptor e o doador perpassa por muitos fatores, desde ser compatível anatomicamente, pela tipagem sanguínea ou até mesmo por demandar de testes minuciosos que são de extrema relevância.

Com isso, de acordo com GARCIA, SOUZA e HOLANDA (2005), o preparo psicológico para esse procedimento é fundamental, visto que as reações são as mais diversas possíveis e dependem muito do significado que o paciente dá ao órgão substituído, suas vivências, preparo para adaptar-se às novas condições de vida, ao conhecimento real ou até mesmo fantasioso do que está acontecendo, dentre outras variáveis. Entretanto, a submissão às sessões recorrentes de hemodiálise são consideradas mais corriqueiras e segundo KOEPE, ARAÚJO (2008):

\footnotetext{
A hemodiálise é um tratamento que remove as substâncias tóxicas e o excesso de líquido acumulado no sangue e tecidos do corpo em conseqüência da falência renal. $\mathrm{Na}$ hemodiálise, o sangue, carregado de toxinas e resíduos nitrogenados, é desviado do paciente para uma máquina, um dialisador, no qual é limpo e, em seguida, devolvido ao paciente. Para que o sangue possa ser retirado, limpo e devolvido ao corpo e é necessário que seja estabelecido um acesso à circulação do paciente. A FAV é um acesso permanente, criado por meios cirúrgicos ao se unir uma artéria em uma veia. (KOEPE; ARAÚJO, 2008, p.148).
}

Com base nos autores citados, é possível compreender, então, que a hemodiálise ocorre através de uma ligação entre o corpo do paciente e uma máquina 
que filtrará o sangue, por intermédio de um acesso, que pode ser por um cateter ou uma fístula artéria venosa (FAV), ou seja, é através da máquina (dialisador) que ocorre o procedimento hemodialítico, responsável por fazer o papel dos rins, limpando e purificando o sangue, devolvendo-o sem impurezas. Em conformidade com VELLOSO (2001), o urêmico crônico expõe em seu corpo as marcas impostas pela doença e pelo tratamento: tem edemas, abscessos vasculares, fissuras e cicatrizes decorrentes da introdução de fístulas e cateteres.

Assim sendo, pensando neste indivíduo renal, a construção em relação às representações sociais, que são estruturadas por cada paciente acerca da sua doença, é muito singular e permeada de inúmeras restrições. É necessário controlar a ingestão de alguns alimentos e, sobretudo, líquidos. Com isso, é notório que o tratamento não é exclusivamente o período em que ele se encontra em sessão, mas é contínuo e carece de transformações. REIS, GUIRARDELLO, E CAMPOS (2008), dissertam que,

As diversas restrições e limitações resultam para o indivíduo em uma perda da sua autonomia, pois a sua vida passa a dependerdeum tratamentoprolongado, doloroso, desgastante, porém, necessário. Tal questão também está relacionada com a incapacidade para o trabalho, resultando em dependência financeira, e do próprio tratamento de hemodiálise que torna o indivíduo dependente de uma máquina e de profissionais capacitados, além das limitações físicas que impossibilitam as pessoas de realizarem atividades cotidianas, como limpeza da casa e fazer compras. (MARTINS, CESARIANO citado por REIS, GUIRARDELLO e CAMPOS, 2008, p.339).

\section{E ainda complementam que,}

A incapacidade para o trabalho também interfere na vida do indivíduo, já que é muito difícil manter vínculos empregatícios formais, tanto pela rotina do tratamento, como pelas complicações e limitações físicas advindas com o problema renal. Tal situação provoca uma diminuição da auto-estima dos indivíduos que passam a ser dependentes financeiramente e precisam, na maioria das vezes, do auxílio de um familiar ou pessoa próxima. A responsabilidade de manter a família é transferida para outra pessoa. (REIS, GUIRARDELLO, E CAMPOS 2008, p.339).

Entende-se que o adoecimento advindo de um diagnóstico crônico implica em mudanças no modo de viver e alteram o cotidiano do paciente. Por sua vez, é notório que o cenário da hemodiálise pode ser compreendido como uma práxis que dispõe de muitas implicações que transcendem a doença. Envolvem questões sociais, emocionais, econômicas, tanto para o próprio paciente quanto para os seus familiares, e conforme, RESENDE, SANTOS, SOUZA e MARQUES (2007) nos colocam, é interessante para que aconteça a adesão ao tratamento abordar e buscar compreender sobre os limites que abarcam as circunstâncias da insuficiência renal crônica.

Acredita-se, a partir da reflexão que nos é provocada mediante a construção do artigo, que enfrentar o fenômeno de adoecimento é um grande desafio do ser humano e, com isso, é essencial que o mesmo possua as informações sobre o seu tratamento, que se responsabilize e se insira nesse processo.

Considerando COSMO e FREITAS (2010), é perceptível que cada paciente é afetado e estrutura a relação diante à sua patologia e tudo o que a mesma inclui de uma maneira muito particular. Alguns infringem certas restrições, questionam o cuidado e a funcionalidade; outros assumem o lugar de depender da máquina de hemodiálise e da equipe; há os que entendema importância do tratamento, mesmo com as adversidades; existem, ainda, os que conseguem manter a esperança de que um dia o funcionamento dos rins irá retornar, excluindo a necessidade do tratamento. Compreende-se que há inúmeras formas de reagir a esse contexto, porém, a cronicidade deixa emergir a impossibilidade de cura e, com a continuidade do tratamento, é natural que muitos questionamentos apareçam e o enfrentamento também passe por modificações.

Diante da impossibilidade da cura médica percebese que alguns pacientes atribuem à religiosidade um papel muito importante, investindo em Deus a confiança de sua melhora. Concomitantemente, outros pacientes reagem frente à sua enfermidade com a ideia de estar passando por um castigo ou uma punição divina.

MATTOS, MARUYAMA (2010), preponderam que mesmo diante de tantas repercussões em relação à doença $\mathrm{e} o$ seu enfrentamento, o paciente submetido às sessões de hemodiálise também apresenta muitas interpretações sobre o significado da sua vida ser mantida à custa de uma máquina, quando o mesmo se depara com a necessidade de ter que depender de um aparelho para sobreviver. Dessa forma, acredita-se ser relevante discorrer que os significados atribuídos também podem ser ressignificados, possibilitando um espaço para outro sentido à experiência vivenciada. Até porque é notório que cada um irá lidar com as intercorrências, o próprio sofrimento da doença e o tratamento em si de uma maneira, visto que essa experiência é marcada pela individualidade.

A convivência com a máquina e o procedimento realizado pode ser compreendido como fundamental pela pessoa acometida pela doença, de acordo com COSMO e FREITAS (2010). Frente à patologia, diante a tantas perdas, o paciente experimenta uma transformação de vida e percebe-se como um ser finito.

\section{Redescobrindo o sentido da vida diante da possibilidade de morte}

Implicar-se frente ao fator irrefutável do morrer não nos parece uma possibilidade enquanto nos encontramos em bom estado de saúde física e mental. 
Dessa forma, nos comportamos como se a morte não fizesse parte da existência humana, porém, estar em constante negação a essa realidade ou fugir de qualquer pensamento sobre a mesma, não a retarda ou a evita.

ARIĖS (2003), em seu livro História da Morte Ocidental, disserta que não é fácil lidarcom afinitude, mas ela espera por todos nós. É notório que o senso comum trata o tema com restrição e, na contemporaneidade, existe certo "tabu" envolvendo a própria palavra morte. As pessoas escolhem termos mais aprazíveis ou, muitas vezes, evita-se falar/pensar sobre, não a evidenciando e, além disso, numa retrospectiva histórica, percebe-se que a concepção do fenômeno morte pelo homem ocidental tem sido elaborada perante um procedimento lento. Para as crianças, por sua vez, habitua-se não abordar o assunto, levá-las a sepultamentos e afins é visto de forma inconcebível, tratando-se sempre o falecimento do outro como um distanciamento voluntário, utilizando-se, por exemplo, os seguintes termos "foi viajar", "foi passear", entre outros, ou aborda-se também de forma folclórica, atribuindo a figura humana a uma estrela no céu, entre outras maneiras, utilizando a personificação.

De inúmeras experiências humanas, acredita-se que nenhuma outra traz mais implicações e desconforto do que a ideia do fim da vida e o temor que ele inspira. A morte provoca um questionamento e traz muitas indagações acerca do encontro com a finitude e suas possibilidades.

Descobrir o sentido da morte não é mais misterioso do que descobrir o sentido da própria existência. Algum tipo de violência, velhice ou doença pode facilmente nos colocar em contato com ela, seja como uma possibilidade ou uma facticidade. A medicina se encarrega de cuidar desse mistério e de contra ele lutar, mesmo sabendo que pode apenas ganhar algumas batalhas, pois não há nenhum alento para vencê-la. (DIAS citado por FEIJOO, 2010, p. 273)

Compreende-se que a morte pode ser fonte para entendimento, esclarecimento e impulsionamento da própria existência, visto que através dela seja possível buscar um sentido à vida. Além disso, ela é inerente ao indivíduo, pois a existência humana é finita. Sendo assim, o encontro com a mesma é um fato inevitável, que é próprio do ciclo vital e, com isso, reconhece-se que o fim da vida vai chegar, porém evita-se pensar em suas implicações sendo experienciado como algo distante, não podendo ser atingível, algo que cause dor e, por esse motivo, deve ser evitada. Em consonância com KOVÁCS (2005), a negação da morte é uma das formas de não nos relacionarmos com as experiências dolorosas.

FREITAS E COSMO (2010) preponderam que doença e morte encontram-se no centro de nossa existência, sendo intrínseca às condições humanas, todavia, quando o indivíduo depara-se com um diagnóstico de uma patologia marcada pela cronicidade faz emergir a possibilidade da própria finitude, percebendo-se também como um ser permeado de fragilidade.

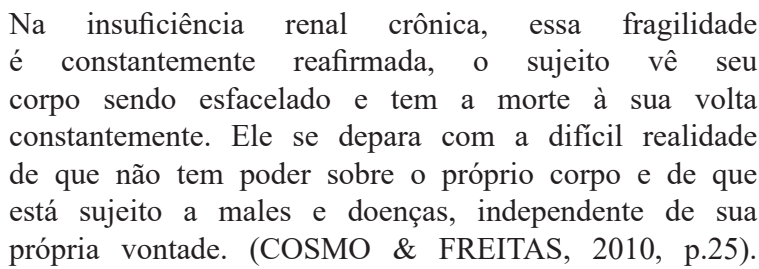
constantemente. Ele se depara com a difícil realidade de que não tem poder sobre o próprio corpo e de que está sujeito a males e doenças, independente de sua própria vontade. (COSMO \& FREITAS, 2010, p.25).

Em concordância com as autoras, mediante o sofrimento que é vivenciado no processo de perdas e limitações na hemodiálise, é possível perceber que o renal crônico tem como associação ao seu tratamento o risco de eventos adversos, abrangendo, inclusive, a própria finitude. Nesse momento, torna-se próximo a possibilidade de morte e o indivíduo vem a ser consciente de que é finito e, muitas vezes, culmina na ausência de expectativas em relação ao futuro. Conforme REIS, GUIRARDELLO e CAMPOS (2008) surge, então, como possível demanda dos pacientes em hemodiálise, a visão da finitude como um fato que está prestes a acontecer, excluindo, assim, pensamentos, ambições e construções futuras, sendo relevante atribuir um novo sentido ao momento em que está experienciando.

Com isso, é imprescindível que seja garantido um espaço para que esses pacientes compartilhem suas questões em relação às suas experiências e seus receios, para que seja possível a ressignificação e elaboração acerca da problemática relatada, considerando individualmente essas pessoas, reconhecendo-as além do sintoma, entendendo-as diante da sua totalidade, como um ser biopsicossocial, com medos, vivências, percepções e que reage de forma imprevisível frente às situações diversas

\section{A relevância da assistência psicológica no ãmbito da hemodiálise}

ANGERAMI (1997), em seu livro "A ética na saúde", escreve que no momento em que estamos inseridos no âmbito hospitalar nos deparamos com muitos limites que são impostos pela própria instituição que precisam ser respeitados e que interferem diretamente com a prática, sendo importante inteirar-se da história e a ideologia da mesma.

A Psicologia Hospitalar foi reconhecida na decisão do Conselho Federal de Psicologia, nomeando-a formalmente como especialidade através da Resolução CFP $\mathrm{n}^{\circ} 14 / 00$, de 20 de Dezembro de 2000. (CFP, 2000).

SIMONETTI (2004) disserta sobre a Psicologia Hospitalar no tocante à sua atuação, que está direcionada à compreensão e o cuidado aos aspectos psicológicos em torno do adoecimento. 
Contudo, torna-se importante compreender como esse cenário se apresenta. COSMO e FREITAS (2010) dissertam que:

\begin{abstract}
Em uma clínica ou hospital é o modelo médico que influencia a conduta dos profissionais que formam a equipe de saúde. Nesse modelo, o paciente, de acordo com RUSSO (2007), é despido de tudo aquilo que marca sua singularidade para ser examinado e tratado. Aborda-se o orgânico, a doença; porém, o que o paciente sente e pensa a respeito do tratamento é deixado para segundo plano ou muitas vezes nem mesmo é considerado relevante. (COSMO\&FREITAS, 2010, p.27).
\end{abstract}

Além disso, COSMO \& FREITAS (2010) complementam que, mediante ao progresso de pesquisas que visam o desempenho do corpo humano, é notório que o indivíduo é percebido como uma parte específica, conforme a especialidade de tal profissional, ou seja, ele não é compreendido em sua totalidade. A tecnologia avançada faz emergir a condição de substituição, as máquinas assumem um lugar de estabelecer os diagnósticos e a comunicação é perdida.

No entanto, salientamos a importância de utilizar todos esses aportes teóricos para explorar e promover uma reflexão acerca da contribuição da Psicologia e como é importante entender o indivíduo em sua integralidade, não subdividindo-o. Pensar na prática do psicólogo, por sua vez, mediante a esses autores, propaga que o paciente seja compreendido em sua dimensão humana. E, como afirma SIMONETTI (2004), a grande e mais importante consequência clínica advinda dessa percepção é que existem pessoas permeadas de particularidades, ao invés de "patologias". SIMONETTI (2004) é muito enfático ao dizer que o interessante é o que é possível fazer com a enfermidade em si, qual o significado que essa pessoa adoecida concede à sua patologia, como acontece o processo de elaboração e, para isso, é necessário possibilitar um espaço de escuta, fazendo com que, assim, surja a palavra.

Dessa forma, SIMONETTI (2004) também se refere à Psicologia no âmbito hospitalar, que vem se desenvolvendo em um novo modelo epistemológico, demandando uma visão abrangente do indivíduo e favorecendo a articulação entre saberes, propiciando, assim, um momento de troca e reflexão em conjunto de demais profissionais que também constituem o hospital.

Em concordância com MOSIMANN E LUTOSA (2011), o psicólogo pode contribuir de forma direta no âmbito hospitalar. Deve-se solicitar à Psicologia não apenas um "fazer por", mas um "fazer com", o que implica em uma prática que acontece em conjunto com as demais áreas de conhecimento que atuam no hospital, propiciando trocas, construções e desconstruções.

Segundo STRAUB (2014), em seu livro "Psicologia da Saúde: Uma Abordagem Psicossocial" entende-se que a Psicologia que atua em Nefrologia abarca a compreensão das condições do tratamento, suas restrições marcadas pela doença, compreendendo o paciente como um ser permeado de particularidades, tendo como objetivo contribuir para minimizar o sofrimento em relação ao contexto em que o mesmo está inserido.

É importante entender que o paciente pode estar experienciando um momento muito complexo, cercado de questionamentos e receios, sendo individualizada a maneira como cada um vivencia uma situação de fragilidade. Torna-se perceptível que, de acordo com as vivências do paciente renal crônico, o processo de luto, no tocante às suas perdas advindas da IRC, também é muito presente.

Com isso, entende-se a relevância da Psicologia, que possibilita a humanização do cuidado e propicia, assim, que o próprio paciente tenha voz, dando espaço à sua singularidade, através de uma escuta qualificada, para que o mesmo possa verbalizar sobre as suas questões. Nesse sentido, compreende-se também, que a função do psicólogo em uma unidade de hemodiálise se estenda em todo o contexto que encontra-se o paciente, mediando os relacionamentos na tríade: paciente família - equipe de saúde.

A prática do psicólogo também visa contribuir e auxiliar ao paciente renal crônico em relação ao momento da descoberta da doença e da necessidade do tratamento, entendendo que cada um responde de uma forma em relação à hemodiálise, necessitando, assim, de suporte para que seja possível compreender como o mesmo está em relação a essa nova realidade e tornando possível, através da assistência, que surja também a possibilidade da ressignificação.

Ressignificar, conforme o dicionário Aurélio (1988), é atribuir um novo significado; O verbo transitivo é empregado pela neurolinguística para caracterizar o processo em que é atribuído um novo sentido às situações da vida, pelas pessoas. De acordo comBEZERRA(2019), ocorre quando as percepções sobre si e o mundo são modificadas. É concedido outro sentido para a situação vivenciada, ressignificando-a mesmo que, para tanto, o sofrer seja inevitável, transformando esse ser humano ao longo de suas experiências. Viktor Frankl disserta em seu livro "Em busca de sentido" (1991), sobre quando nos deparamos com algumas situações que causam dor, sofrimento e uma possibilidade de morte eminente, onde passamos a refletir não exclusivamente sobre o sentido da vida, mas também questionamos o porquê desse sofrimento. $\mathrm{O}$ autor ainda disserta a respeito de quando não podemos mais modificar uma situação, somos desafiados a modificar nós mesmos.

São singulares as representações sociais vivenciadas por cada indivíduo, as queixas referentes ao seu processo de hospitalização, às suas limitações, às mudanças, às dificuldades relacionadas ao enfrentamento da sua patologia e o tratamento, ao meio em que vivem à 
sua relação com o seu ambiente laboral, seus familiares, à sua questão social, econômica, entre inúmeras queixas que o mesmo possa dissertar. Desse modo, acredita-se que ofertar o atendimento psicológico seja relevante, porém, é dado ao próprio paciente o direito de escolha, fazendo com que, mais uma vez, ele possa se afirmar mediante o que ele acredita ser necessário, de acordo com o seu desejo e que não seja mais uma imposição, diante de tantas.

Por fim, o atendimento psicológico na hemodiálise pode apresentar diversas possibilidades e, como já foi dito, atua sobre o impacto da doença no indivíduo e sua família, propiciando um espaço de fala, escuta e reflexão, permitindo ainda, que o mesmo seja compreendido em sua totalidade, além da possibilidade de desconstruções e novas construções diante do contexto de perdas, sejam elas parciais ou totais, a compreensão da finitude frente à realidade de cada um, entre outras contribuições. Mediante a esse cenário, que por vezes se caracteriza como invasivo, é de suma relevância que seja possível a aproximação do paciente a ele mesmo, restituindo-lhe um lugar, visto que o ambiente em que se encontra a despersonalização é muito presente. Ele deixa de ter o seu próprio nome e a sua identidade e passa a ser um número de leito ou então alguém que é estigmatizado por apresentar uma determinada doença, seja ela crônica ou não. Todavia, o indivíduo não é apenas a sua patologia, ele transcende, vai além.

A prática do profissional de Psicologia visa, então, a elaboração de uma nova estruturação do paciente, a manutenção do tratamento, oferece suporte no enfrentamento de sua condição, criação de estratégias para que resulte e promova qualidade de vida, desfrutando desse espaço da assistência psicológica como uma possibilidade de ressignificação do processo que está imerso. Em conformidade com COSMO E FREITAS (2010), portanto, o fazer psicológico nesse cenário é ofertar mais saúde, apesar da doença'.

\section{Considerações finais}

Perpetramos uma reflexão frente ao cenário do hospital, especificamente no setor da hemodiálise, as implicações que a Insuficiência Renal Crônica e o tratamento estabelecem aos pacientes e seus familiares, a contribuição do psicólogo nesse contex to e a relevância da assistência psicológica como possibilidade de ressignificação e elaboração.

É possível, portanto, através desse artigo refletir acerca das fragilidades, limitações, perdas, restrições e readequações que podem ser vivenciadas por pacientes renais crônicos em relação à situação de dependência em que vivem, seja no cuidado da equipe, da medicação, o bom funcionamento da máquina de hemodiálise, a alimentação, as representações sociais, dentre outras situações, deixando emergir, portanto, a perda do controle sob a vida, constatação essa que pode culminar em muitos questionamentos, receios e incertezas sobre o sentido da sua existência.

Elucidamos diante deste panorama de doença renal que o paciente, muitas vezes, não é compreendido como um ser humano e sim como um órgão, em específico apenas um rim que está "com defeito", porém, nesse mesmo contexto, quando esse paciente é compreendido em sua totalidade e lhe é ofertado um espaço de fala e escuta, essa figura é desconstruída, o olhar da equipe técnica passa a não ser somente para a doença e, sim, para o indivíduo como um todo, repleto de anseios, medos, dúvidas, tristezas e dificuldades, que lhe são particulares. É visto, portanto, como uma pessoa e não um número de leito estigmatizado, como uma patologia.

Concluímos que ao psicólogo cabe vários papéis que serão importantes, se apropriando do recurso primordial de que se dispõe: a escuta. Propicia, assim, um espaço para a singularidade emergir, sendo possível fazer com que o indivíduo, em uma conjuntura de perda e aflição, onde imagina que não encontrará motivos para existir, encontre essas razões dentro de si mesmo, ressignificando, portanto, a sua existência, que está interligada a todo momento com a sua finitude e no espaço da assistência psicológica é que a elaboração dessa questão se inicia. Seu sofrimento, então, é acolhido, mas também questionado, possibilitando uma abertura diante do irremediável da morte, da perda.

A atuação do profissional de Psicologia segue a direção de minimizar o sofrimento e o impacto da patologia na vida do paciente e da família, que estão submetidos por conta da doença, tentando impedir os efeitos iatrogênicos na busca de garantir a direção do tratamento junto com a equipe, compreendendo como as relações e os vínculos estão sendo estruturados, a forma como cada um reage aos eventos e as novas limitações que são atribuídas. É relevante que o psicólogo esteja engajado em seu exercício profissional, sempre atualizando seus conhecimentos diante da temática, repensando e aperfeiçoando sua prática, para que seja ofertado o melhor que lhe for possível.

Ao paciente nesse contexto lhe é concedido o respeito em relação à sua posição em lutar ou não contra a doença, mas entendendo o momento de auxiliá-lo na construção de um novo sentido à vida e à sua patologia, dentro de suas possibilidades e diante das limitações que são impostas pelo processo de hospitalização e de seu tratamento, auxiliando, também, na descoberta de uma melhor maneira para enfrentá-las.

Em suma, à luz do que foi abordado, foi possível corroborar para uma reflexão acerca da relevância da assistência psicológica na hemodiálise, visto que pode ser considerado um espaço que possibilita a promoção de bem-estar, reintegração social, reorganização 
emocional e reestruturação do paciente. Além disso, auxiliar na manutenção do seu tratamento, oferecer suporte na construção e na criação de estratégias para que o enfrentamento da doença resulte e promova uma melhor qualidade de vida. Através do mesmo, foi possível somar conhecimentos acadêmicos, sendo de grande valia no âmbito profissional e pessoal. $\mathrm{O}$ artigo confirma a relevância do tema e necessidade de novas pesquisas.

\section{Referências}

ALMEIDA, Raquel Ayres de; MALAGRIS, Lucia Emmanoel Novaes. A prática da psicologia da saúde. Rev. SBPH vol.14 no. 2, Rio de Janeiro Jul/Dez. - 2011

ALMEIDA, Laina Silva de PALMEIRA, Aline Tonheiro. O sofrimento psíquico, a doença renal crônica e as possíveis contribuições do trabalho do psicólogo. Cientefico. V. 18, N. 37, Fortaleza, jan./jun. 2018.

ANGERAMI-CAMON, V.A. (Org.). A ética na saúde. São Paulo: Pioneira Thomson Learning, 1997.

. Psicologia Hospitalar teoria e prática. Cengage Learning. 2010.

. E a Psicologia Entrou no Hospital. São Paulo: Pioneira. 1996. ARIĖS, Philippe. História da Morte no Ocidente. Rio de Janeiro: Ediouro, 2003

1977

Da idade média aos nossos dias. Rio de Janeiro: Francisco Alves, 1982

O homem diante da morte vol. 2. Rio de Janeiro: Francisco Alves,

BARROS, Elvino. et. al. Nefrologia: Rotinas, diagnóstico e tratamento $3^{\mathrm{a}}$ edição. Porto Alegre: Artmed, 2006

BEZERRA, Karina Viviani; SANTOS, Jair Lício Ferreira. O cotidiano de pessoas com insuficiência renal crônica em tratamento hemodialítico. Rev Latino-am Enfermagem julho-agosto; 16(4), 2008.

BEZERRA, Larissa Campos. Crise e ressignificação existencial: um impulso para o crescimento, 2019.

BRASIL, Ministério da Saúde. Diretrizes clínicas para o cuidado ao paciente com doença renal crônica - drc no sistema único de saúde. Brasília- df, 2014

BRASIL, Ministério da Saúde. Biblioteca Virtual em Saúde. 2015.

CATTAI, Glauco Barnez Pignata; ROCHA, Fabiana Alonso; JUNIOR, Nelson Nardo; PIMENTEL, Giuliano Gomes de Assis. Qualidade de vida em pacientes com insuficiência renal crônica - SF-36. Cienc Cuid Saude; 6(Suplem. 2):460-467, 2007.

COMBINATO, Denise Stefanoni; QUEIROZ, Marcos de Souza. Morte: uma visão psicossocial. Estudos de Psicologia, 11(2), 209-216, 2006

CONSELHO FEDERAL DE PSICOLOGIA. Resolução CFP N ${ }^{\circ}$ 02/01 Brasília: CFP, 2000

\section{CONSELHO FEDERAL DE PSICOLOGIA. Resolução Nº 02/01. 2001.}

DUARTE, Laís; HARTMANN, Silvana Pinto. A autonomia do paciente com doença renal crônica: percepções do paciente e da equipe de saúde. Rev. SBPH vol. 21 no. 1, Rio de Janeiro - Jan./Jun. - 2018.

FEIJOO, A. M. L. C. de.Tédio e finitude: da filosofia a psicologia. Belo Horizonte: Fundação Guimarães Rosa, 2010.

FERMI, M. R. V. Manual de diálise para enfermagem. Rio de Janeiro: Medsi, 140p. 2003.

FERREIRA, A. B. H.. Dicionário Aurélio Básico da Língua Portuguesa Rio de Janeiro: Nova Fronteira, 1988.
FRANKL, Viktor. Em busca de sentido. Editora Vozes, 1991.

FREITAS, Paula Pereira Werneck de; COSMO,Mayla. Atuação do Psicólogo em Hemodiálise. Rev. SBPH v.13 n.1, Rio de Janeiro, Jun. 2010.

GARCIA, Maria Lúcia Pinheiro; SOUZA, Ângela Maria Alves \& HOLANDA, Teresa Cristina. Intervenção Psicológica em uma Unidade de Transplante Renal de um Hospital Universitário. PSICOLOGIA CIÊNCIA E PROFISSÃO, 25 (3), 472-483, 2005.

KOEPE, Giselle Barcellos Oliveira; ARAÚJO, Sílvia Teresa Carvalho de. A percepção o do cliente em hemodiálise frente à fístula artério venosa em seu corpo. Acta Paul Enferm; 21(N'mero Especial): 147-51, 2008.

KOVACS, Maria Júlia. Educação para a morte. Psicol. cienc. prof., Brasília, v.25,n.3, p. 484-497, 2005

KUBLER-ROSS, Elisabeth. Sobre a morte e o morrer. 4. Ed. São Paulo: M. Fontes, 1991

MARTINS MRI, Cesarino CB. Qualidade de vida de pessoas com doença renal crônica em tratamento hemodialítico. Rev Latino-am Enfermagem, setembro-outubro; 13(5): 670-6 2005 .

MARTINS, Marielza R. Ismael; CESARINO, Claudia Bernardi; Qualidade de vida de pessoas com doença renal crônica em tratamento hemodialítico. Rev Latino-am Enfermagem, setembro-outubro; 13(5): 670-6, 2005.

MATTOS Magda; MARUYAMA Sônia Ayako Tao. A experiência de uma pessoa com doença renal crônica em hemodiálise. Rev Gaúcha Enferm., Porto Alegre (RS) set;31(3):428-34, 2010.

MOSIMANN, Laila T. Noleto Q.; LUSTOSA, Maria Alice. A Psicologia hospitalar e o hospital. Rev. SBPH vol.14 no. 1, Rio de Janeiro - Jan/Jun. $-2011$.

NASCIMENTO, Fernando A. Figueira. Uma contribuição às reflexões sobre os aspectos emocionais e o papel do psicólogo na Hemodiálise. Rev. SBPH vol.16 no. 1, Rio de Janeiro - Jan./Jun. - 2013.

QUINTANA, Alberto Manuel; MÜLLER, Ana Cláudia. Da saúde à doença: representações sociais sobre a insuficiência renal crônica e o transplante renal. Psicologia Argumento, Curitiba, v. 24, n. 44 p. 73-80, jan./mar. 2006.

REIS, Carla Klava dos; GUIRARDELlO, Ednêis de Brito; CAMPOS, Claudinei José Gomes. $O$ indivíduo renal crônico e as demandas de atenção. Rev Bras Enferm, Brasília- maio-jun; 61(3): 336-41, 2008.

RESENDE, Marineia Crosara de; SANTOS, Francisco Assis dos ; SOUZA, Melissa Macedo de;MARQUES, Thatianna Pereira . Atendimento psicológico a pacientes com insuficiência renal crônica: em busca de ajustamento psicológico. Psic. Clin., Rio de Janeiro, vol.19, n.2, p.87 - 99, 2007.

ROMÃO JÚNIOR, J.E. Doença Renal Crônica: Definição, Epidemiologia e Classificação. Jornal Brasileiro de Nefrologia. 2004; 26:1-3. http:// www.bjn. org.br/details/1183/pt-BR/doenca-renal-cronica--definicao-epidemiologiae-classificacao. Acesso em: 10 de Maio de 2020.

SIMONETTI, A. Manual de psicologia hospitalar: o mapa da doença. São Paulo: Casa do Psicólogo, p. 33-118, 2004.

SOCIEDADE BRASILEIRA DE NEFROLOGIA. Censo da Sociedade Brasileira de Nefrologia. 2017.

SCHRAMM, Fermin Roland. Morte e finitude em nossa sociedade: implicações no ensino dos cuidados paliativos. Revista Brasileira de Cancerologia, 48(1): 17-20, 2002.

STRAUB, R. A Psicologia da Saúde: Uma Abordagem Psicossocial. (3a ed.). Porto Alegre: Artmed, 2014

VELloso, Rosana Laura Martins. Efeitos da hemodiálise no campo subjetivo dos pacientes renais crônicos. Cogito, 3, 73-81,2001 